\title{
HIGH SCHOOL CHOICES AND THE GENDER GAP IN STEM
}

\author{
David Card \\ A. Abigail Payne \\ Working Paper 23769 \\ http://www.nber.org/papers/w23769
NATIONAL BUREAU OF ECONOMIC RESEARCH
1050 Massachusetts Avenue
Cambridge, MA 02138
September 2017

Data for this project were made available by the Ontario Ministry of Education and the Ontario University Applications Centre pursuant to data confidentiality agreements with the Public Economics Data Analysis Laboratory at McMaster. We are extremely grateful to Olesya Kotlyachkov and PEDAL staff for assistance in processing the data. The views expressed herein are those of the authors and do not necessarily reflect the views of the National Bureau of Economic Research.

NBER working papers are circulated for discussion and comment purposes. They have not been peer-reviewed or been subject to the review by the NBER Board of Directors that accompanies official NBER publications.

(C) 2017 by David Card and A. Abigail Payne. All rights reserved. Short sections of text, not to exceed two paragraphs, may be quoted without explicit permission provided that full credit, including (C) notice, is given to the source. 
High School Choices and the Gender Gap in STEM

David Card and A. Abigail Payne

NBER Working Paper No. 23769

September 2017

JEL No. I20,J16

\begin{abstract}
$\underline{\text { ABSTRACT }}$
Women who graduate from university are less likely than men to specialize in science, technology, engineering, or math (STEM). We use detailed administrative data for a recent cohort of high school students in Ontario, Canada, combined with data from the province's university admission system to analyze the dynamic process leading to this gap. We show that entry to STEM programs is mediated through an index of STEM readiness based on end-of-highschool courses in math and science. Most of the gender gap in STEM entry can be traced to differences in the rate of STEM readiness; less than a fifth is due to differences in the choice of major conditional on readiness. We then use high school course data to decompose the gap in STEM readiness among university entrants into two channels: one reflecting the gender gap in the fraction of high school students with the necessary prerequisites to enter STEM, and a second arising from differences in the fractions of females and males who enter university. The gender gap in the fraction of students with STEM prerequisites is small. The main factor is the lower university entry rate by men - a difference that is due to the lower fraction of non-science oriented males who complete enough advanced level courses to qualify for university entry. We conclude that differences in course-taking patterns and preferences for STEM conditional on readiness contribute to male-female differences in the rate of entering STEM, but that the main source of the gap is the lower overall rate of university attendance by men.
\end{abstract}

\author{
David Card \\ Department of Economics \\ 549 Evans Hall, \#3880 \\ University of California, Berkeley \\ Berkeley, CA 94720-3880 \\ and NBER \\ card@econ.berkeley.edu
}

\author{
A. Abigail Payne \\ Melbourne Institute: Applied Economic \\ \& Social Research \\ University of Melbourne \\ Level 5, FBE Building \\ 111 Barry St \\ Carlton Victoria 3010 \\ Australia \\ abigail.payne@unimelb.edu.au
}


In most countries a smaller fraction of women than men graduate with a degree in science, technology, engineering, or math (STEM). Figure 1, for example, shows the female share of all bachelor degree graduates in 8 OECD countries in 2011-2012, and the shares in science and engineering. In every country but Japan, women represent a majority of graduates but less than half of those are in science or engineering. ${ }^{1}$ This under-representation has important consequences not only for the science professions but also for the disparity in economic status between men and women. An analysis of recent data for the U.S. and Canada, for example, suggests that the gender gap in the likelihood of graduating with a STEM-related degree explains up to a fifth of the wage gap between younger college-educated men and women in both countries. ${ }^{2}$

In this paper we use rich administrative data on high school courses and grades for a cohort of students from the province of Ontario to study the choices that lead to a 13 percentage point gender gap in the probability of enrolling in a STEM program at university. ${ }^{3}$ Although not all the students who enter a STEM program will graduate with a STEM degree, attrition rates from STEM programs appear to be similar for males and females (Dooley, Payne and Robb, 2012). Moreover, most programs have a rigorous multi-year course sequence so students who do not initially enroll in a STEM program have little chance of graduating with a

\footnotetext{
${ }^{1} \mathrm{~A}$ large existing literature documents and analyzes the gender gap in STEM fields - see e.g., Ceci, Williams and Barnett (2009), Hill, Corbett and St. Rose (2010), Ceci et al. (2014), and Sax et al (2016). Kahn and Ginther (2017) provide a review of this literature.

${ }^{2}$ See Appendix Table 1, where we present regression models for wages of females and males with a bachelor degrees or more in the 2006 Canadian Census and the 2009 U.S. American Community Survey.

${ }^{3}$ As explained below, we define STEM programs to include engineering, physical and natural sciences, math, computer science, health science (including nursing), environmental science, architecture, and agriculture.
} 
STEM degree. Thus, we take entry to university in a STEM program as a proximate endpoint for understanding the gender gap in STEM.

Our analysis builds on three features of the Ontario education system that are broadly similar to those in many other countries that do not use national tests for college admission. First, high school graduates apply to specific programs at universities in the province (e.g., computer science at the University of Toronto), enabling us to easily identify those who are likely to graduate with a STEM degree. Second, applicants are ranked on the basis of their grades in standardized courses offered in the fourth year of high school, with each program specifying a set of prerequisite courses. No other factors are considered for admission to the vast majority of programs. ${ }^{4}$ As a result, courses and grades in the last year(s) of high school fully determine a student's opportunities at the university level. A third feature of the Ontario system is that the math courses needed for STEM readiness are (essentially) limited to students who have taken prerequisite math classes in earlier grades. This allows us to identify students who are on track to graduate with the needed courses to enter STEM programs at university.

We use two complementary data sets to analyze the gender gap in STEM entry. We begin with data on 400,000 university entrants from 2005 to 2012 . We show that STEM entry for both genders is mediated through a simple measure of STEM readiness based on completion of at least 3 STEM-related classes in the last year(s) of high school. ${ }^{5}$ Matriculants who fail to meet this minimal standard have only a 5\% chance of entering any STEM program in the province, while those who are STEM ready have an $80 \%$ chance of enrolling in STEM, with

\footnotetext{
${ }^{4}$ A few specialized arts and music programs require students to submit a portfolio or similar material.

${ }^{5}$ As explained below, Ontario high schools offer various "tracks" for 12 th grade classes. The critical courses required for entry to university STEM programs are in the university preparation track. Students can and do often take a fifth year of high school to take or retake these courses.
} 
similar rates for men and women. Most of the gender gap in STEM entry is therefore attributable to the gender gap in STEM readiness, rather than to differences in program choices conditional on readiness.

In the second stage of our analysis we use detailed transcript data for a province-wide cohort of public high school students to study the determinants of STEM readiness. At the end of high school, females have nearly the same overall rate of STEM readiness as males, and slightly higher average grades in the prerequisite math and science courses. The mix of STEM related courses taken by men and women is different, however, with a higher concentration of women in biology and chemistry and a lower concentration in physics and calculus.

We perform a simple counterfactual exercise to decompose the gender gap in the STEM readiness rate into two channels: one representing the difference in the fractions of females and males who enter university with the needed prerequisites for STEM readiness, and another representing the difference in overall rates of entering university between females and males. ${ }^{6}$

The first channel is small: 14.5 percent of females enter university with the necessary courses to qualify as STEM ready, compared to 15.3 percent of males. The main driver of the gender gap is the fact that many more females (44\%) than males (32\%) enter university. Simply assuming that non-STEM ready females had the same university entry rate as non-STEM ready males would narrow the gender gap in the fraction of university entrants who are STEM ready from 14 percentage points to less than 2 percentage points.

While lower rates of university entry by non-STEM-oriented males accounts for most of the gender gap in STEM readiness, it is still surprising that females end up with a slightly lower

\footnotetext{
${ }^{6}$ Mathematically, $\mathrm{P}(\mathrm{SR}=1 \mid \mathrm{Reg})=\mathrm{P}(\mathrm{SR}=1 \& \operatorname{Reg}) / \mathrm{P}(\mathrm{Reg})$ where $\mathrm{SR}=1$ indicates $\mathrm{STEM}$ readiness and Reg indicates "registration" (i.e., formally matriculating) at university. Thus the gap in STEM
} 
rate of STEM readiness than males, since females are more likely to be on track to achieve STEM readiness in earlier years of high school. ${ }^{7}$ We therefore examine the determinants of STEMrelated course taking conditional on course choices and achievement in $11^{\text {th }}$ grade. We find significant gender gaps in the probability of taking physics and calculus that are partially offset by a gap in the opposite direction for biology. A simple counterfactual analysis suggests that if females achieved the same STEM readiness rate as males conditional on being on/off track at the end of 11th grade, they would complete high school and enter university with a 2 percentage point higher STEM readiness rate, instead of the 1 point shortfall we observe.

Finally, we examine the characteristics of non-STEM ready students. Relatively few nonscience-oriented men complete high school with enough advanced-level courses in humanities and social sciences to qualify for university. This gap is evident as early as 9th grade, where males are less likely than females to complete the academic track classes that lead to these advanced level courses.

Overall, our analysis suggests that many higher-achieving female students tend to select non-STEM courses in the last years of high school, despite having done well in math in $11^{\text {th }}$ grade. These choices may detract from their being able to register in STEM programs. The effect of these choices is modest, however, relative to the impact of the fact that so many more non-STEM-oriented women enter university than their male counterparts - a gap that is traceable back to choices made at the beginning of high school.

readiness depends on the differences between males and females for both the numerator and denominator of this expression.

${ }^{7}$ A common stereotype is that females have lower math ability than males. However, in most countries including the U.S. and Canada, the gender gap in mean math performance at high 


\section{Institutional Background and Classification of STEM Programs}

\section{a. Background}

Ontario students enter their first year of high school (9th grade) at age 14 or 15 and are expected to graduate in four years, though many spend a fifth year. ${ }^{8}$ At each grade (or "level" in the terminology of the province) most courses are offered in two parallel tracks: academic and applied. Students who choose a given track in level 1 (9th grade) math or language arts typically follow the same track in later years although there are options to switch tracks. Level 4 (12th grade) courses in languages, math, and science are split into "university preparation" (UP) and "college preparation" tracks, with entry to UP math and science classes limited to students who have completed academic track math at level 3. There are also "mixed" courses in areas such as history and geography that fulfill the requirements for university entry, and other courses for students who do not intend to pursue tertiary education (see Ontario Ministry of Education, 2011, for an overview).

As might be expected in this tracked system, course selections in early grades have a substantial effect on the probability of entering university. Card and Payne (2015), for example, show that the university entry rate is about $70 \%$ for males and females who complete 9 th grade academic track courses in math and language arts with grades of $70 / 100$ or better, while those who fail to complete these two gateway courses have less than a $10 \%$ entry rate. ${ }^{1}$

In their final year of high school students can apply to one of the 20 universities in the province though a centralized system known as the Ontario University Application Centre

school is small -- see Hyde et al. (2008) for an analysis using NAEP scores, and Else-Quest, Hyde, and Linn (2010) for comparisons across countries using PISA and TIMMS scores.

${ }^{8}$ Historically Ontario had a five-year high school system which was eliminated in 2003. Students, however, are allowed to remain enrolled for additional years.

${ }^{1}$ The threshold of 70 reflects the standard culture in Ontario high schools that $70+$ is needed to 
(OUAC). Applications are made to specific programs -- for example, Life and Physical Sciences at Queen's University - or even specific subprograms (e.g., Biochemistry). Each program or subprogram lists a set of required UP course prerequisites on the OUAC web site. ${ }^{9}$ Applicants to a program/subprogram are ranked on the basis of their grades in these courses and their top 6 qualifying level 4 courses and admitted until the program is full. Students who accept an offer of admission normally "register" in that program at the start of the fall semester.

\section{b. Classification of STEM Programs}

A preliminary question in any analysis of STEM participation is which university programs to classify as STEM. Several alternative classifications are used by various government non-governmental agencies, differing mainly in whether to include social sciences and medicalrelated fields such as nursing. Our classification, which is summarized in Table 1, includes the following programs under STEM: engineering, physical sciences, natural sciences, math, computer science, nursing, environmental science, architecture, and agriculture. This list is very similar to the one adopted by Beede et al. (2011) for US programs, apart from the fact that we include nursing in STEM, whereas they do not. ${ }^{10}$ Our choice is based on the fact that nursing programs in Ontario require at least 3 UP courses in math, chemistry, and biology -- the same prerequisites as many other STEM programs -- and typically award a Bachelor of Nursing Science degree. As documented in Appendix Table 2, holders of degrees in health sciences (including nursing) account for $12 \%$ of all younger women with final bachelor's degree in Canada, and half

reflect a threshold of understanding the material in the course.

${ }^{9}$ For example, applicants to the BA Honours Program at Carleton University wishing to enter Economics must have UP courses in English and Advanced Functions; Calculus is strongly advised. 
of those with a STEM-related degree. Moreover, health sciences graduates are among the most highly paid of all degree holders -- second only to engineering graduates - so we believe it is important to include nursing in the definition of STEM.

\section{Pathways for STEM Entry}

In this section we use data on multiple cohorts of university entrants to develop a measure of STEM readiness which summarizes the high school preparation of different students. We then use this measure in Section III to classify students in our high school cohort data set as STEM ready or not, and study the determinants of STEM readiness.

We follow this two-step approach because our high school data set lacks information on the program choices of university entrants: we know only whether a whether a student registered at an Ontario university. Given the sequential nature of the choice problem faced by students, however, we believe there is little or no loss in using a two-step approach. Students have to choose their level 4 courses before they apply to university, and only know their admission offers after they have finished high school. If STEM entry were fully mediated by STEM readiness (i.e., STEM readiness were both necessary and sufficient to enter a STEM program) then a student's choice problem in the last year of high school could be reduced to a decision about whether to take the needed classes to become STEM ready. ${ }^{11}$ While our measure of STEM readiness does not fully mediate STEM entry, it is close to a necessary

\footnotetext{
${ }^{10}$ In contrast, a recent classification published by the US Bureau of Labor Statistics includes nursing in STEM - see Jones (2014).

${ }^{11}$ Formally, consider a dynamic choice problem with 2 periods: a first period in which students choose high school courses, and a second period in which students register in university or not, and if they register choose a STEM program or not. If STEM readiness is necessary and sufficient for entering a STEM program in the second period, then the first period decision problem can be reduced to one that assigns payoffs to STEM readiness and non-readiness.
} 
requirement. Moreover, we construct the measure to match the stated entry requirements for most STEM programs in the province, so it is clearly sufficient. We also believe it closely approximates any "rule of thumb" that guidance counselors would recommend to students in choosing their courses in the final year of high school.

\section{a. Course Taking Patterns for Registrants}

We obtained data from OUAC on high school graduates who registered in an Ontario university between 2005 and 2012. The data set includes information on the level 4 courses taken by each applicant and their grades in these courses. In addition it includes demographic information and the university program into which the student initially registered, which we classify as STEM or not using the categories in Table 1.

Appendix Table 3 summarizes the characteristics of the university entrants in the OUAC data. We limit attention to registrants who were attending a public high school in Ontario and were between 17 and 20 years of age at the time of their application. We also require that students have complete information on their level 4 courses and grades. The resulting sample includes 413,656 new university entrants, $57.5 \%$ of whom are female. Overall, $30.3 \%$ of females (a total of 72,033 women) and $42.5 \%$ of males (a total of 74,763 men) enrolled in a STEM program. Note that the gap in the proportion of students within each gender group who register in STEM is large (12 percentage points) despite the fact that nearly half (49\%) of STEM registrants are female. This reflects the much larger fraction of females than males who enter university in the province.

Table 2 presents information on the fractions of registrants who took each of the 5 main STEM-related UP courses in their last year(s) of high school, and the relationship between 
course participation and STEM entry among female and male students. There are two main math classes (advanced functions and calculus) and three main science courses (biology, chemistry, and physics). Over $90 \%$ of both male and female STEM registrants took functions and chemistry. By comparison, only about one-half of female STEM registrants took physics and less than $60 \%$ of male STEM registrants took biology. These patterns are consistent with well-known gender differences in entry to different types of STEM programs. Female students in Ontario, like those in the U.S., are more likely to enter life sciences (which generally require functions, chemistry, and biology as prerequisites), whereas males are more likely to enter engineering programs (which generally require functions, calculus, and physics). ${ }^{12}$

In light of the stated prerequisites for many STEM programs and the course taking patterns in Table 2 we developed a simple indicator of STEM readiness based on successful completion of advanced functions, at least one of biology and calculus, and at least one of chemistry and physics. This simple measure captures the typical prerequisite set for both life sciences programs (functions, biology, chemistry) and engineering/physical sciences programs (functions, calculus, physics), so we consider it sufficient for STEM readiness. It also appears to be close to a necessary condition for STEM entry. As shown in the bottom row of Table 2, about $89 \%$ of females and $92 \%$ of males who registered in a STEM program met our measure of STEM readiness, whereas only $5 \%$ of females and $6 \%$ of males who failed to meet our measure were able to enter a STEM program. ${ }^{13}$

\footnotetext{
${ }^{12}$ Hill et al. (2010, Figure 5) show that first year female students in the U.S. are more likely to indicate an intended major in biological sciences than men, and less likely to indicate an intended major in engineering.

${ }^{13} \mathrm{An}$ examination of STEM programs entered by students who are not STEM ready shows that many of these are programs like environmental science and kinesiology that fall outside the
} 


\section{b. Gender Differences in STEM readiness and STEM-entry}

STEM readiness status largely determines whether students will be accepted into a STEM program if they apply. Not all students who are STEM ready, however, apply to STEM programs or choose to enter one if accepted. We therefore ask: how much of the gender gap in the probability of registering in a STEM program can be attributed to the difference in STEM readiness, versus the choice to pursue a STEM program, conditional on STEM readiness?

To proceed, note that that the probability of choosing a STEM program (denoted by "STEM") conditional on registering (denoted by "Reg") can be decomposed as:

$$
\begin{aligned}
P(\text { STEM } \mid \text { Reg })= & P(S T E M \mid S R=1, \text { Reg }) \times P(S R=1 \mid \text { Reg }) \\
& +P(S T E M \mid S R=0, \text { Reg }) \times P(S R=0 \mid \text { Reg })
\end{aligned}
$$

where SR is an indicator for STEM readiness. The average values of the terms in this expression for females and males are presented in Table 3. As shown in the second row of the table, $30.3 \%$ of female students register in STEM compared to $43.5 \%$ of males - a 13.2 percentage point gap. STEM readiness rates differ substantially between male and female registrants (with an overall gap of 13.8 percentage points) while rates of entering STEM conditional on $\mathrm{SR}=1$ or $\mathrm{SR}=0$ are fairly similar for females and males, suggesting that most of the difference in STEM entry is attributable to STEM readiness.

The simple counterfactuals in the lower part of the table give a more precise breakdown. As a starting point, note that for both females and males, the second term in equation (2) is:

$$
\mathrm{P}(\mathrm{STEM} \mid \mathrm{SR}=0, \mathrm{Reg}) \times \mathrm{P}(\mathrm{SR}=0 \mid \operatorname{Reg}) \approx 0.032
$$

traditional natural and life sciences and do not require at least 3 STEM-related UP courses as 
Thus, the gender gap in STEM registration is attributable only to the first term in equation (1). Assuming STEM ready females had the same probability of registering in STEM rate as STEM ready males, the gap would be 11.2 percentage points ( $85 \%$ of its actual value); whereas assuming males had the same rate as females, the gap would be 10.5 percentage points (81\%). These calculations imply that less than one-fifth of the registration gap is attributable to differences in choices made by female and male registrants, conditional on STEM readiness. The majority (81-85\%) is due to differences in the rate of STEM readiness.

\section{c. A Closer Look at STEM-entry by STEM ready Students}

A possible concern with the counterfactual analysis in Table 3 is that our measure of STEM readiness does not account for differences in the grades received by females and males. In particular, if females and males have different average grades in their math and science classes they may be admitted to STEM programs at different rates, contributing to the gender gap in STEM entry rates between STEM ready women and men.

Table 4 presents some summary information on course grades of female and male registrants in our OUAC sample. To simplify comparisons between students who took different combinations of level 4 courses, we first convert a student's grade in a given course into a percentile rank within the distribution of grades for registrants who took that course in a given cohort. We then construct the average rank of each student's 6 best grades, and the average rank of their top 3 STEM-related classes. ${ }^{14}$ Since female students have different average grades

prerequisites.

${ }^{14}$ For STEM-related classes (advanced functions, calculus, biology, chemistry, and physics) we compute ranks within the distribution of scores for all students who took the class (in a given cohort or gender/cohort) but we only report average ranks in top 3 STEM-related courses for students who are STEM ready, and therefore took at least 3 STEM-related courses. 
than males, we also constructed a "within-gender and cohort" rank for each student's grade in each course. Averages of these ranks are only comparable within a gender group.

The upper panel of Table 4 compares the average ranks of female and male students in their top 6 classes. The tendency for female students to earn higher course grades in high school is reflected in their higher within-cohort rank: 0.52 versus 0.47 for males. For both gender groups STEM ready students have higher average grades than the overall population of registrants, with a 9 percentile gap among females and an 8 percentile gap among males. STEM ready students who actually enter STEM programs (columns 3 and 6) have even higher mean ranks, though the differences relative to the STEM ready subpopulation are small ( +1 percentile points).

The lower panel of Table 4 compares the average ranks of the top 3 STEM-related courses for STEM ready students. Females have a slightly lower average rank on their top 3 math and science classes (1 percentile point lower than males). Thus, their higher average rank for their top 6 classes is driven by higher grades in non-STEM-related courses. Students who register in STEM have about 3 percentiles higher average scores in their STEM-related courses than the overall STEM ready subpopulation, with a similar degree of selectivity for females and males.

With these average ranks in hand, we turn to the question of how differences in grades affect the gender gap in the probability of registering in a STEM program. Table 5 presents a set of linear probability models for the event of registering in STEM, fit to the combined population of STEM ready male and female registrants. We begin in column 1 with a benchmark model that includes only a dummy for female gender. As noted in row 4 of Table 3, the gender gap in STEM registration is -5.0 percentage points. The model in column 2 introduces cohort effects, a 
complete set of dummies for each high school in the province, and student level demographics, including age dummies and controls for foreign born status, main language spoken at home, and gifted/special needs status. These controls widen the gender gap slightly to 5.8 percentage points.

In column 3 of Table 5, we introduce controls for each student's average rank on his or her top six level 4 classes, and the average rank based on his or her top three math/science classes. The estimated coefficients on these two averages are highly significant and show strong comparative advantage in program selection. Students with higher grades in STEMrelated courses are more likely to enter STEM, holding constant their overall top 6 grades, whereas students with higher overall grades are less likely to enter STEM, holding constant their top 3 math/science grades. ${ }^{15}$ Controlling for both sets of average ranks, the gender gap in STEM entry falls to 1.7 percentage points. The narrowing of the gender gap relative to the specification in column 2 is explained by the higher average rank of females on their top 6 classes (contributing -2.9 points), their lower average rank on their top 3 math/science classes (contributing -0.9 points), and small changes in the coefficients of several of the control variables (contributing -0.3 points). Interestingly, the most important factor is therefore female's comparative advantage in non-STEM-related courses. ${ }^{16}$

\footnotetext{
${ }^{15}$ The average rank on a student's top 6 courses is roughly an average of their average rank on their top 3 STEM-related courses and their average rank on their top 3 non-STEM courses. Thus the coefficients in column 3 imply that the probability of registering in STEM varies with $0.47 \times$ (Average Rank on Top 3 STEM-related classes) - $0.26 \times$ (Average Rank on Top 3 non-STEM classes).

${ }^{16}$ We also estimated the model in column 3 allowing an interaction between a female dummy and the coefficients on the two rank variables. In this specification, the effects of rank on the top 3 STEM-related courses and the top 6 courses are 0.79 and -0.57 for males, and 0.68 and 0.47 for females. Thus the relative effects of the ranks in STEM courses and all 6 courses are similar for males and females, but course ranks exert a smaller effect on females ( $85 \%$ as large).
} 
We interpret the comparisons of ranks in Table 4 and the regression models in Table 5 as supportive of two conclusions. First, STEM readiness is a relatively good summary of the differences in end-of-high school qualifications of female versus male students. In particular, conditional on STEM readiness, females have only very slightly lower average grades in their top 3 math and science courses, offset by higher grades on their non-STEM courses. Second, the relatively small (5 percentage point) gender gap in the probability of registering in STEM conditional on STEM readiness falls to under 2 percentage points when we account for the higher grades that STEM ready females have in non-STEM related courses, and their slightly lower grades in science and math courses. Arguably, then, our summary of high school courses that relies only on courses taken and ignores grades overstates the importance of genderrelated preference for STEM versus non-STEM classes.

\section{Preparing for STEM at High School}

\section{a. High School Cohort Data}

We now turn to our high school cohort data, focusing on course-taking in the last year of high school and the determinants of STEM readiness. Our analysis is based on administrative records for all students who enrolled in 9th grade in the 2005-2006 academic year at any publicly funded Ontario high school. ${ }^{17}$ These records include information on courses and grades taken over the next 5 years (i.e., up to and including the 2009/2010 school year) as well as information on whether the student applied to an Ontario university or vocational college, and

\footnotetext{
${ }^{17}$ This includes so-called "public" high schools, which are non-religious and open to all students, and Catholic high schools, which are fully government-funded in Ontario. Within each of these two categories there are high schools where the main language is English and others where the main language is French.
} 
whether they registered in either type of institution. ${ }^{18}$ We also have access to some personal information, including age and gender, indicators for gifted or special needs status, and nativity. Finally, we merge the student records with data on the characteristics of the school the student attended in 9th grade, including an indicator for whether it is a Catholic school, the share of students in the 9th grade cohort who drop out or disappear from our sample, and the share of 9th grade students classified as non-English/French language learners. We also merge in information on the characteristics of the neighborhood around the school, including distance to the nearest university and vocational college, mean household income, fraction of single parent families, and the share of visible minorities. ${ }^{19}$

Since our focus is on university entry, we limit attention to students who are observed taking level 4 courses within 5 years of entering high school. Summary statistics for our resulting analysis sample are reported in Appendix Table 4. Overall, we have 135,261 students, $50.3 \%$ of whom are female. Eighty percent of the females in the sample applied to an Ontario vocational college or university within 5 years of entering high school, compared to $70 \%$ of males. Interestingly, this gender gap in entry to tertiary education is entirely a result of the higher fraction of females than males who enter university (44\% versus $32 \%)$. The rates of entry to vocational college are nearly the same for females and males (25\% versus $26 \%$ ).

\footnotetext{
${ }^{18}$ Course information is available for students who move between publicly funded high schools, but not for those who leave the publicly funded system (i.e., move out of province or switch to a private school).

${ }^{19}$ We use the so called "Forward Sortation Area" (FSA) which is based on the first three digits of the postal code of the high school to identify the neighborhood. Statistics Canada supplies tabulations of the 2006 census by FSA that we use to measure neighborhood characteristics.
} 


\section{b. Course Taking Patterns at Level 4 and the Gap in STEM readiness}

Table 6 shows the fractions of female and male students in our high school sample who took each of the 5 main STEM-related UP courses, as well as their average grades in these courses and the average grades received by two subgroups: those who achieved STEM readiness, and those who achieved STEM readiness and registered in university. In the last rows of the table we also show the fractions of students that achieved STEM readiness, the fractions that registered in university, and the STEM readiness rate among registrants.

Two key patterns emerge from the table. First, as would be expected given the comparisons among registrants in Table 2, females are more likely to take biology in their last year of high school, whereas males are more likely to take physics. Males are also somewhat more likely to take advanced functions and calculus, while females are somewhat more likely to take chemistry. Despite these differences, at the end of high school $17.9 \%$ of females are STEM ready, compared to $18.8 \%$ of males -- a gap of only 0.9 percentage points. Interestingly, the gender gap in the fraction that is STEM ready and registers in university is comparable: $14.5 \%$ of females versus $15.3 \%$ of males. Since many more females than males register in university, however, the difference in the probability of being STEM ready, conditional on registering, is 14.1 percentage points - very close to the 13.8 point gap we measured in our OUAC sample of registrants.

A second finding is that in all five STEM-related UP courses, female course-takers have either the same or slightly higher grades than males. As would be expected, however, STEM ready students have higher grades than average course-takers, and STEM ready registrants have even higher grades, with a higher selectivity differential for males than females in math and physics. Accounting for these selection effects, STEM ready females have slightly lower average 
grades than STEM ready males in functions and physics, slightly higher average grades in biology and chemistry, and about the same average grades in calculus.

We are now in a position to assess the role of STEM readiness at the end of high school in determining the gap in STEM readiness among registrants. Using the same notation as in equation (1), the probability of being STEM ready $(S R=1)$ conditional on registering in university (Reg) can be decomposed as:

$$
\mathrm{P}(\mathrm{SR}=1 \mid \operatorname{Reg})=\mathrm{P}(\operatorname{Reg} \& \mathrm{SR}=1) \times \mathrm{P}(\mathrm{SR}=1) / \mathrm{P}(\mathrm{Reg})
$$

The average values of the terms in this expression for females and males in our high school cohort are shown in Table 7. The difference in the numerator of equation (2) between female and male students is small: $14.5 \%$ versus $15.3 \%$. The gap in the denominator is much larger (43.5\% versus $32.2 \%)$. Since the denominator is just the numerator plus a component attributable to the behavior of non-STEM ready students, it is clear that most of the gap in the probability of STEM readiness among registrants is due to the much higher rate of registration of non-STEM ready females (35.3\%) than males (20.9\%).

Columns 4 and 5 summarize the outcomes for female students and the resultant gender gaps if we assume that non-STEM ready females had the same probability of entering university as non-STEM ready males. Under this counterfactual the university entry rate of females would fall to $31.6 \%$ and the gender gap in STEM readiness of entrants would fall from 14.1 percentage points to 1.6 percentage points. An alternative counterfactual is to assume that non-STEM ready males have the same probability of entering university as non-STEM ready females. This would raise the registration rate of males to $44 \%$ and narrow the gap in the STEM readiness of entrants to 1.5 percentage points. Under either counterfactual about $90 \%$ of the STEM readiness gap is due to the higher rate of university entry by non-STEM ready females. 


\section{c. Level 3 Math Achievement and Course Taking Patterns at Level 4}

Although the gender gap in STEM readiness at the end of high school is relatively small, the lower rate of participation in UP math and science courses by female students is potentially surprising given that in earlier years of high school females perform somewhat better than males in academic track math. Based on patterns of entry to level 4 STEM courses we decided to categorize students as on track for STEM readiness if they achieved a grade of 70 or higher in level 3 academic math, and "off track" if they scored less than 70 or failed to take the course. Using this classification, the total share of students who are STEM ready and enter university after high school (i.e., the numerator of equation 2) can be decomposed as:

$$
\begin{aligned}
\mathrm{P}(\mathrm{SR}=1 \text { \& Reg=1 }) & =\mathrm{P}(\operatorname{Reg} \mid \mathrm{SR}=1, \text { Ontrack }) \times \mathrm{P}(\mathrm{SR}=1 \mid \text { Ontrack }) \times \mathrm{P}(\text { Ontrack }) \\
& +\mathrm{P}(\operatorname{Reg} \mid \mathrm{SR}=1, \text { Offrack }) \times \mathrm{P}(\mathrm{SR}=1 \mid \text { Offtrack }) \times \mathrm{P}(\text { Offtrack })
\end{aligned}
$$

The first expression represents the contribution of on-track students to the overall share of STEM ready registrants. The second expression represents the contribution of off-track students.

Panel $A$ of the table shows the mean values of 3 first terms in equation (3) for female and male students, while panel B shows the corresponding last 3 terms. Comparisons of the various terms for females and males lead to two key conclusions. First, since only $5-6 \%$ of students who are off-track at the end of $11^{\text {th }}$ grade become STEM ready, the overall contribution of off-track students is small (2.5 percentage points for females and 3.2 percentage points for males -- see row 8 ). Second, among students who are on track, the probability of becoming STEM ready is substantially lower for females (54.8\%) than males (63.4\%), offsetting the higher fraction of females who are on-track. 
Columns 4 and 5 illustrate a simple counterfactual exercise where we assume that females have the same probabilities of achieving STEM readiness as males, conditional on being on or off track at the end of 11th grade. This shift would raise the overall fraction of female students who are STEM ready and register in university to $16.9 \%$ and convert the 0.8 percentage point shortfall of females relative to males into a 1.7 point advantage for females. Holding constant the other terms would then narrow the gender gap in the fraction of registrants who are STEM ready from 14.1 percentage points to 10.1 percentage points. Most of the gain (75\%) comes from students who are on track for taking STEM-related math and science classes.

This analysis suggests that a higher fraction of females than males who have been doing well in advanced math up to 11th grade decide to opt out of STEM-related courses. This difference can account for a modest share (around one-fifth) of the gap in STEM readiness between females and males, relative to the counterfactual in which well-prepared females pursued advanced track math and science courses at the same rate as well-qualified males.

\section{d. University Entry by non-STEM ready Students}

As a final step in our analysis, we examine the group of students who fail to take the minimum set of math and science courses to be STEM ready. In view of the standards for university admission in Ontario, we classify students as university ready if they successfully complete at least 5 qualifying level 4 classes (i.e., UP or mixed track courses). We then divide all high school students in our cohort sample into 3 groups: university-ready and STEM ready ${ }^{20}$; university-ready and not STEM ready; and not university ready.

\footnotetext{
${ }^{20}$ Our definition of STEM readiness requires that students have successfully completed at least 3 UP math and science classes. A small fraction of these students ( $4 \%$ of females and $7 \%$ of males) do not have enough other qualifying courses to meet our threshold for university-readiness.
} 
The entries in panel A of Table 9 show that $56 \%$ of all female students are university ready by their last year of high school, versus $49 \%$ of males. Females and males have very similar rates of being university and STEM ready (17.2\% versus $17.4 \%)$. Thus, virtually all of the gender gap in the overall rates of university readiness is attributable to the smaller fraction of males who are university-ready but not STEM ready.

The entries in panel $\mathrm{B}$ of Table 9 give university registration rates for all students and those in each of the three subgroups. As noted in Table 7, females have much higher overall rates of entry into university than males (45\% versus $32 \%$ ). Conditional on readiness status, however, the gender gaps in registration rates are small. Registration rates for females and males who are university and STEM ready are $83 \%$ and $85 \%$, respectively, while the rates for those who are university ready but not STEM ready are also quite similar ( $72 \%$ versus $70 \%)$. Moreover, university entry rates for students who fail to meet the minimum threshold of at least 5 qualifying courses are very low for both groups -- 1.3\% for females and $1.6 \%$ for males. These patterns mean that the shortfall in the overall university registration rate for males is driven by the lower fraction of men who are university ready but not STEM ready. Indeed, the decompositions in the bottom two rows of Table 9 suggest that virtually all of the shortfall can be explained this way.

We have also examined the course distributions for male and female students in each of the three broad categories introduced in Table 9. Figure 2 shows the distribution of course titles for each student's top 5 UP and mixed courses for males and females who are STEM ready (upper panels) and university ready but non-STEM ready (lower panels). Comparing the two upper two panels, we see that STEM ready females are more likely to have biology and chemistry in their top 5 courses, while STEM ready males are more likely to have physics and 
calculus in their top 5. Around $80 \%$ of both gender groups have UP English or French in their top 5 courses, but otherwise STEM ready students take relatively few social science and humanities classes. In contrast, students who are university ready but not STEM ready have very few math or science courses in their top 5 , and focus instead on social science and humanities classes like geography, history, law, and philosophy. Within this group the gender differences are relatively small, especially compared with the very wide gap in course taking patterns relative to the STEM ready group.

We also show (in pink) the fractions of university-ready but not STEM ready males and females who completed academic track level 3 (11th grade) math with a grade of 70 or higher. This rate is just under $30 \%$ for both females and males, suggesting that most of the students of either gender who end up being university ready but not STEM ready had "opted out" of UP math well before the end of high school.

The third group of non-university ready students includes those who fail to take enough level 4 classes to obtain a high school graduation diploma ( $15 \%$ of all females in our high school sample and $20 \%$ of all males) and those who obtain a diploma but concentrate on applied courses that prepare them for vocational college and/or direct entry to the workforce $(30 \%$ of all females and $41 \%$ of all males). Most of the students in this group take few if any UP courses and are very far from the threshold needed to achieve university readiness. 
Card and Payne (2015) show that much of the gender gap in university entry in our Ontario high school sample can be predicted by differences in course selections and grade outcomes in ninth grade. Specifically, they show that students of either gender who fail to achieve a grade of 70 or better in at least one of the two main academic track courses in ninth grade (math and languages) have less than a 10\% chance of entering university within the next 5 years. Most of the students who fail to meet this threshold take non-academic track courses in levels 2-4 and end up with relatively few UP or mixed courses in their last years of high school. The 15 percentage point higher fraction of males than females who fall below the threshold is remarkably similar to the gender gap in university readiness that explains the gender gap in overall university entry and the lower share of female students who are STEM ready when they enter university.

\section{Summary and Conclusions}

To summarize our main findings, Table 10 combines the decomposition results in Tables 3,7 , and 9 to show the sources of the 13.2 percentage point gender gap in the fraction of newly entering university students who enroll in a STEM program. Overall, 2.1 percentage points are attributable to a lower rate of entering a STEM major by STEM ready females than males (row 1a); 1.7 percentage points are attributable to the slightly lower fraction of females than males who are STEM ready at the end of high school and the slightly lower fraction of STEM ready females who enter university (row 2a); and 9.4 percentage points are attributable to the higher fraction of non-STEM ready females who finish high school with enough qualifying classes to be university ready. 
In addition to these main findings, our analysis points to several other key differences between female and male students. On average, females have about the same average grades in UP math and sciences courses as males, but higher grades in English/French and other qualifying courses that count toward the top 6 scores that determine their university rankings. This comparative advantage explains a substantial share of the gender difference in the probability of pursing a STEM major, conditional on being STEM ready at the end of high school.

We also find that females are more likely than males to be on track to take STEMrelated courses in their last year of high school, as measured by obtaining a grade of 70 or higher in level 3 academic track math. But fewer of these females take enough STEM-related UP classes to achieve STEM readiness, so females end up slightly less STEM ready at the end of high school. This slippage presents a potential opportunity for policies to raise the fraction of females who complete three or more math and science courses in level 4 , though we suspect that again the forces of comparative advantage may compel at least some of the on track female students to opt out of STEM courses.

A final pattern revealed by our analysis is the wide divergence in course-taking between students who are STEM ready at the end of high school and those who are university ready but not STEM ready. Very few of the latter group are on the margin of STEM readiness, and less than $30 \%$ were on track for STEM courses at the end of 11th grade. University-bound students in Ontario schools tend to specialize early, suggesting that any attempt to raise the fraction of STEM ready students will require significant changes in student course taking starting at the earliest years of high school. 
References

Beede, David, Tiffany Julian, David Langdon, George McKittrick, Beethika Khan, and Mark Doms. "Women in STEM: A Gender Gap to Innovation." U.S. Department of Commerce Economics and Statistics Administrations. ESA Issue Brief 04/11. 2011.

Card, David and A. Abigail Payne. Understanding the Gender Gap in Postsecondary Education Participation: The Importance of High School Choices and Outcomes. Toronto: Higher Education Quality Council of Ontario, 2015.

Carnevale, Anthony P., Nicole Smith and Michelle Melton. STEM: Science Technology Engineering Mathematics. Washington, DC: Georgetown University Center on Education and the Workforce. 2011

Ceci, Stephen J., Wendy M. Williams and Susan M. Barnett. "Women's Underrepresentation in Science: Sociocultural and Biological Considerations." Psychological Bulletin 135(2), March 2009: 218-261.

Ceci, Stephen J., Donna K. Ginther, Shulamit Kahn, and Wendy M. Williams. "Women in Academic Science A Changing Landscape." Psychological Science in the Public Interest 15(3), December 2014: 75-141.

Dooley, Martin, A. Abigail Payne and Leslie Robb. "Persistence and Academic Success in University." Canadian Public Policy 38(3): 315-339.

Else-Quest, Nicole M., Janet Shibley Hyde, and Marcia C. Linn. "Cross-national Patterns of Gender Differences in Mathematics: A Meta-Analysis." Psychological Bulletin 136(1), 2010: 103-127.

Hill, Catherine, Christianne Corbett and Andresse St. Rose. Why So Few?: Women in Science Technology Engineering and Mathematics. Washington DC: AAUW, 2010.

Hyde, Janet S., Sara M. Lindberg, Marcia C. Linn, Amy B. Ellis, and Caroline C. Williams. "Gender Similarities Characterize Math Performance." Science 321, July 2008 : 494-95.

Jones, John I. "An Overview of Employment and Wages in Science, Technology, Engineering, and Math (STEM) Groups." In Beyond the Numbers: Employment and Unemployment 3(8) April 2014.

Kahn, Shulamit and Donna K. Ginther. "Women and STEM." In Susan L. Averett, Laura M. Argys, and Saul D. Hoffman, editors, The Oxford Handbook on the Economics of Women. New York: Oxford University Press, 2017.

Ontario Ministry of Education. "The Ontario Curriculum Grades 9-12: Course Descriptions and Prerequisites." Available at www.edu.gov.on.ca/eng/document/curricul/secondary/descript/descri9e.pdf.

Sax, Linda J, M. Allison Kanny, Jerry A. Jacobs, Hannah Whang, Dayna S. Weintraub, and Amber Hroch. "Understanding the Changing Dynamics of the Gender Gap in Undergraduate Engineering Majors: 19712011. Research in Higher Education 57 (2016): 570-600. 
Figure 1: Percent Females Among All University Graduates and In Engineering and Science (2011 or 2012)

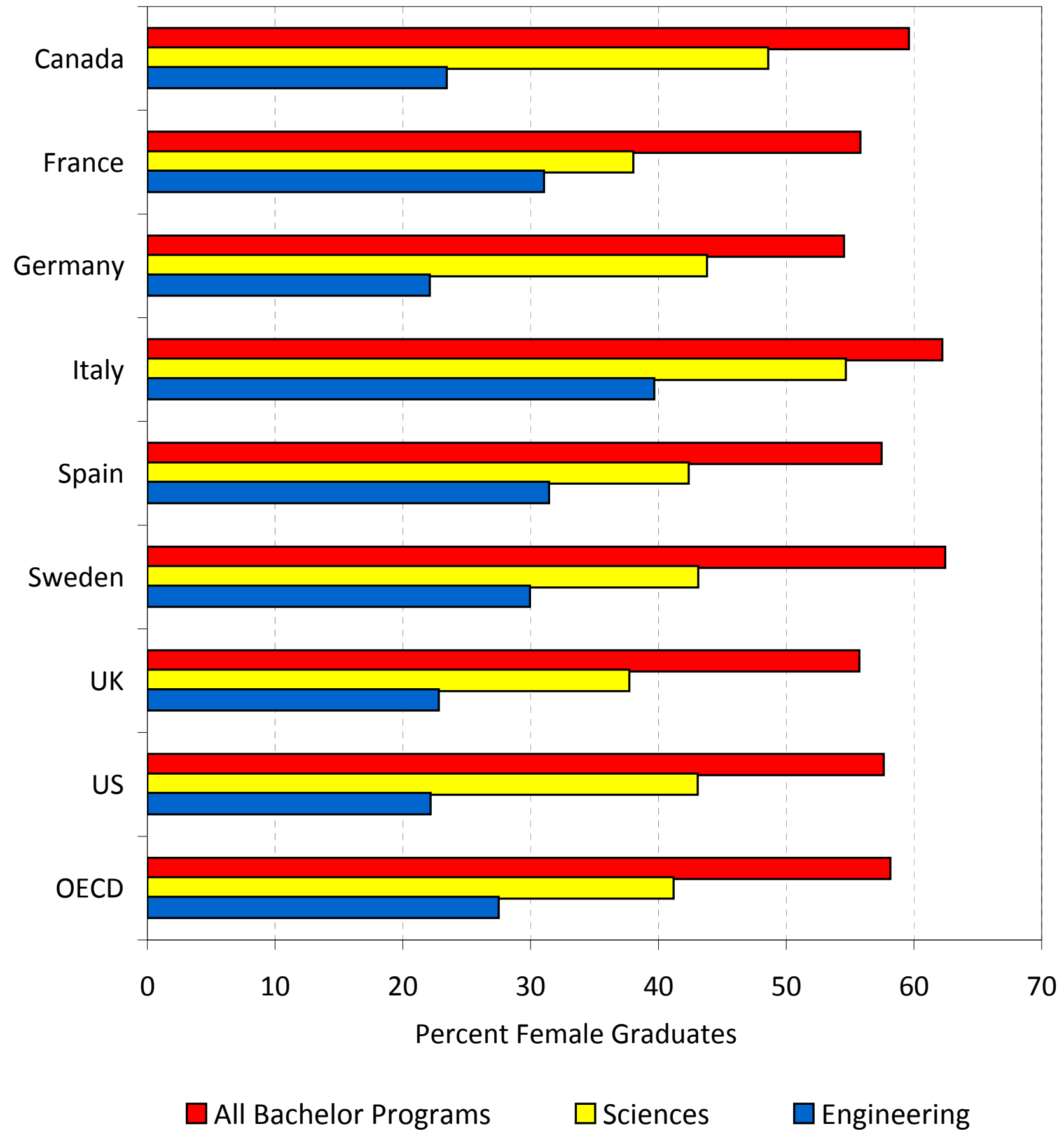

Source: OECD (2016). 
Figure 2: Distributions of Top 5 Level 4 Courses for University Ready Students, Classified by Gender and STEM Readiness
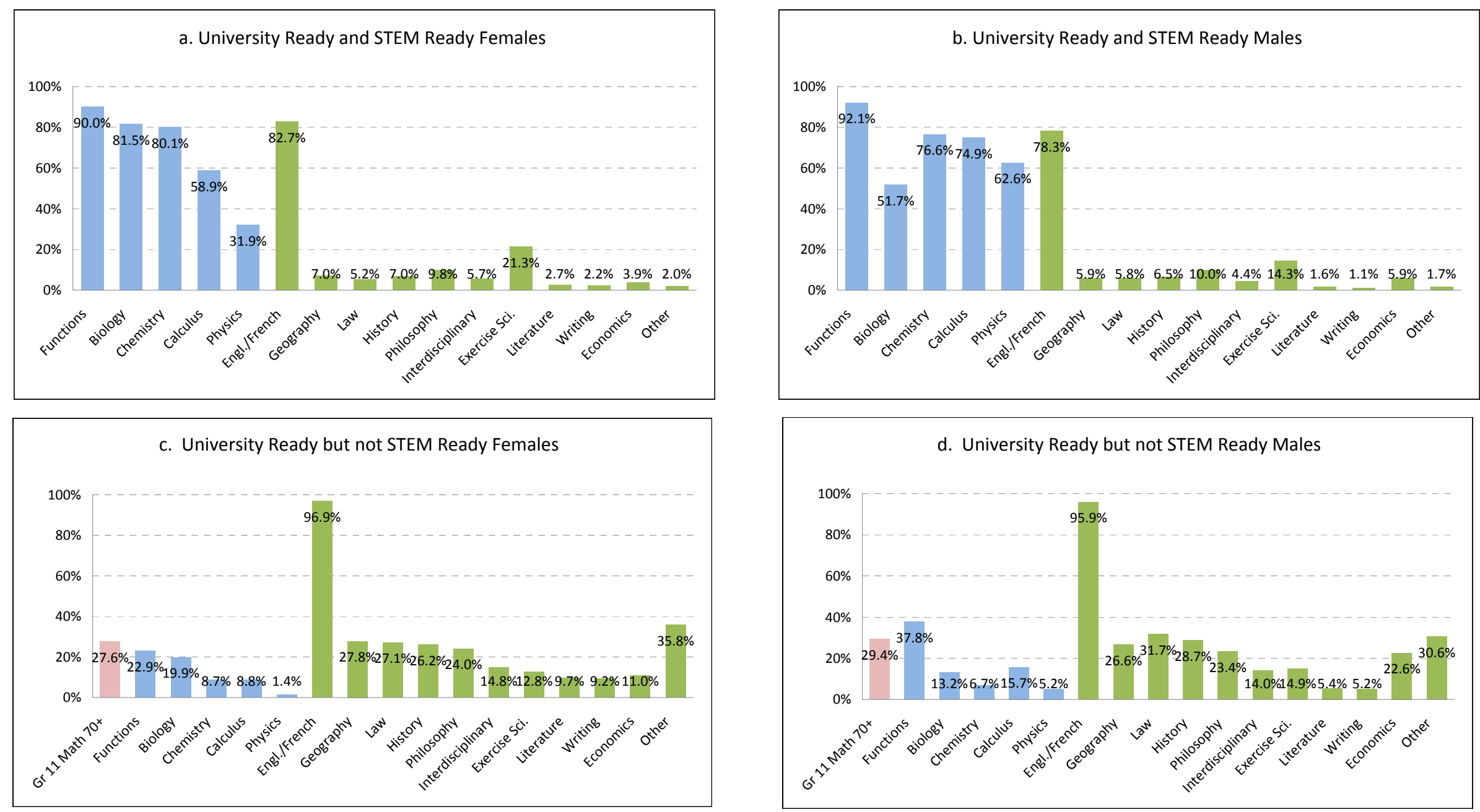
2. Physical/Natural Sciences
1. Engineering

Univ. of Waterloo, Chemical Engineering (co-op)

Univ. of Ottawa, GeNie Informatique

McMaster Univ., Engineering

Univ. of Guelph, Biomedical Engineering

Ryerson Univ., Medical Physics

Carleton Univ., Science: Honours

Western Univ., Health Sciences

Univ. of Toronto Scarborough, Co-op Neuroscience

York Univ., Kinesiology and Health Science BSc

Trent Univ., Biology

Nipissing Univ., BSc Psychology

Univ. of Windsor, BFS Forensic Science

York Univ. Science: Computational Mathematics

McMaster Univ., Mathematics and Statistics

Ryerson Univ., Mathematics and Its Applications

Wilfrid Laurier Univ., BSc Honours Financial Mathematics

4. Computer Science and Information Technology

5. Nursing/Midwifery

6. Environomental Science

7. Architecture

8. Agriculture
Queen's Univ., Nursing

Univ. of Ottawa, BScN Nursing

York Univ. (Collaborative BSc)

Univ. of Ottawa, Computer Science Honours

Univ. of Toronto St. George, Computer Science

Lakehead Univ. BSc Forestry Honours

Univ. of Waterloo, Environmental Sciences

Ryerson Univ., Architectural Science

Carleton Univ., Industrial Design

Univ. of Guelph, BSc Agriculture

Trent Univ., Sustainable Agriculture and Food Systems

Note: Authors' classification based on university programs students report in OUAC system. 
Table 2: Gender Differences in Course Taking Patterns and Registration in STEM programs

\begin{tabular}{|c|c|c|c|c|c|c|}
\hline & \multicolumn{3}{|c|}{ Female Students } & \multicolumn{3}{|c|}{ Male Students } \\
\hline & $\begin{array}{l}\text { Percent of All } \\
\text { Registrants } \\
\text { Taking Course } \\
\text { (1) }\end{array}$ & $\begin{array}{c}\text { Percent of STEM } \\
\text { Registrants } \\
\text { Taking Course } \\
\text { (2) }\end{array}$ & $\begin{array}{c}\text { Percent Register } \\
\text { in STEM if Took } \\
\text { Course } \\
\text { (3) }\end{array}$ & $\begin{array}{l}\text { Percent of All } \\
\text { Registrants } \\
\text { Taking Course } \\
\text { (4) }\end{array}$ & $\begin{array}{l}\text { Percent of STEM } \\
\text { Registrants } \\
\text { Taking Course } \\
\text { (5) }\end{array}$ & $\begin{array}{c}\text { Percent Register } \\
\text { in STEM if Took } \\
\text { Course } \\
\text { (6) }\end{array}$ \\
\hline Functions & 54.1 & 91.9 & 51.5 & 73.1 & 97.0 & 57.7 \\
\hline Calculus & 28.4 & 59.3 & 63.4 & 49.0 & 79.4 & 70.4 \\
\hline Biology & 43.9 & 90.2 & 62.3 & 35.1 & 57.2 & 70.8 \\
\hline Chemistry & 39.3 & 93.5 & 72.2 & 49.3 & 90.3 & 79.6 \\
\hline Physics & 18.8 & 49.4 & 80.0 & 42.0 & 78.0 & 80.8 \\
\hline STEM-ready ${ }^{\mathrm{a} /}$ & 35.3 & 88.8 & 76.3 & 49.1 & 91.8 & 81.3 \\
\hline
\end{tabular}

Note: based on 2005-2012 university applicants in OUAC database who register in university in fall after their application, with valid student and course information. Sample is restricted to students age 17-20 at the time of application from publicly funded Ontario high schools. Sample has 237,743 females (30.3\% of whom register in STEM programs) and 175,913 males (42.5\% of whom register in STEM programs).

${ }^{a}$ STEM readiness designation is based on having successfully completed at least 3 Level 4 math and science classes: functions plus at least one of calculus and biology and at least one of chemistry or physics. 
Table 3: Decomposition of Gender Differences in STEM Registration

\begin{tabular}{|c|c|c|c|c|}
\hline & $\begin{array}{l}\text { All } \\
(1)\end{array}$ & $\begin{array}{c}\text { Females } \\
(2)\end{array}$ & $\begin{array}{c}\text { Males } \\
(3)\end{array}$ & $\begin{array}{c}\text { Gender Gap } \\
\text { (4) }\end{array}$ \\
\hline Number of University Registrants & 413,656 & 237,743 & 175,913 & -- \\
\hline Percent Register in STEM Program & 35.9 & 30.3 & 43.5 & -13.2 \\
\hline \multicolumn{5}{|c|}{ STEM readiness and STEM Registration ${ }^{a /}$} \\
\hline $\begin{array}{l}\text { Percent of All Registrants who } \\
\text { are STEM ready }\end{array}$ & 41.2 & 35.3 & 49.1 & -13.8 \\
\hline $\begin{array}{l}\text { Percent Register in STEM if } \\
\text { STEM ready }\end{array}$ & 78.9 & 76.3 & 81.3 & -5.0 \\
\hline $\begin{array}{l}\text { Percent Register in STEM if } \\
\text { not STEM ready }\end{array}$ & 5.3 & 4.9 & 6.3 & -1.4 \\
\hline \multicolumn{5}{|c|}{ Part of STEM registration gap attributable to STEM readiness gap: } \\
\hline \multicolumn{4}{|c|}{ a. Using Male Rate of STEM Registration if STEM ready } & -11.2 \\
\hline \multicolumn{4}{|c|}{ b. Using Female Rate of STEM Registration if STEM ready } & -10.5 \\
\hline \multicolumn{5}{|c|}{ Part of STEM registration gap attributable to registration gap conditional on readiness: } \\
\hline \multicolumn{4}{|c|}{ a. Using Female Rate of STEM readiness } & -1.8 \\
\hline \multicolumn{4}{|l|}{ b. Using Male Rate of STEM readiness } & -2.5 \\
\hline
\end{tabular}

Note: See note to Table 2.

${ }^{\mathrm{a}}$ STEM readiness designation is based on having successfully completed at least 3 Level 4 math and science classes -- see Table 2. 
Table 4: Average Rank of Course Grades of Female and Male Students

\begin{tabular}{|c|c|c|c|c|c|}
\hline \multicolumn{3}{|c|}{ Female Students } & \multicolumn{3}{|c|}{ Male Students } \\
\hline & & STEM & & & STEM \\
\hline & & Ready \& & & & Ready \& \\
\hline & STEM & Register in & & STEM & Register in \\
\hline All & Ready & STEM & All & Ready & STEM \\
\hline (1) & $(2)$ & (3) & (4) & (5) & (6) \\
\hline
\end{tabular}

\section{A. Average Ranking (0 to 1) of Top 6 Level 4 Classes:}

Within-cohort

0.52

0.61

0.62

0.47

0.55

0.56

Within-cohort/gender

0.50

0.59

0.60

0.50

0.59

0.59

\section{B. Average Ranking (0 to 1) of Top 3 STEM related Classes:}

Within-cohort

Within-cohort/gender

Number of Students
0.50

$-\quad 0.50$

237,743

83,939

64,044

0.53

0.53

$--$

$--$

175,913
0.51

0.54

Notes: See Table 2 for sample information and definition of STEM readiness. Table entries represent mean rank of top 6 level 4 classes (panel A) or of top 3 STEM related courses (panel B) for student group in column heading. Samples in columns 1 and 4 exclude students who fewer than 6 Level 4 classes. 
Table 5: Models For Probability of Registering in STEM Related Program, Conditional STEM-readiness

Dependent Variable $=1$ if Register in STEM related Program

(1)

(2)

(3)

Female Indicator $(\times 100)$

$-5.0$

$-5.8$

$-1.7$

$(0.2)$

(0.2)

Within-cohort Rank of Top 3

$--$

0.73

0.42

STEM Courses

(0.01)

(0.01)

Within-cohort Rank of Top 6

$\begin{array}{ll}-- & - \\ -- & -\end{array}$

$--$

$-0.52$

$-0.34$

Level 4 Courses

(0.01)

Indicator: 4 STEM courses

$--$

$--$

0.20

(0.01)

Indicator: 5 STEM courses

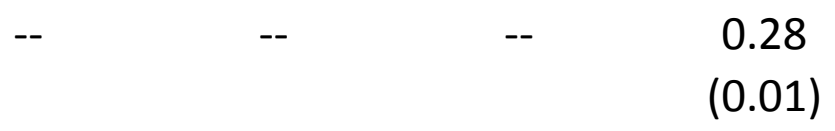

Age, Year and High School

Effects?

no

yes

yes

yes

Other Controls (Language,

Foreign Born, Gifted/special

no

yes

yes

yes

Note: standard errors in parentheses. Table reports linear probability model coefficients for event of registering in STEM related program. Sample is 170,288 STEM ready students. Models in columns 2-4 include dummies for age, graduating cohort, student's main language, foreign-born status, and high school. See Table 2 for sample information. 
Table 6: STEM related Course Taking and Grades in Last Year of High School

Females Males Gender Gap

(1)

(2)

(3)

STEM-related Course Taking in Last Year(s) of High School

a. Functions (math)

Percent of Cohort Taking Course

28.1

$30.2-2.1$

Mean Grade (all takers)

80.6

80.6

0.0

Mean Grade if STEM ready

82.3

82.6

$-0.3$

Mean Grade if STEM ready and Register in Univ.

82.7

83.3

$-0.6$

\section{b. Calculus}

Percent of Cohort Taking Course

Mean Grade

16.8

20.5

$-3.7$

Mean Grade if STEM ready

80.9

80.4

0.5

Mean Grade if STEM ready and Register in Univ.

81.8

81.4

0.4

\section{c. Biology}

Percent of Cohort Taking Course

82.1

82.1

0.0

Mean Grade

25.7

15.3

10.4

Mean Grade if STEM ready

82.4

82.1

0.3

Mean Grade if STEM ready and Register in Univ.

83.4

83.0

0.4

\section{d. Chemistry}

Percent of Cohort Taking Course

83.8

83.5

0.3

Mean Grade

21.5

19.4

2.1

Mean Grade if STEM ready

80.9

80.2

0.7

Mean Grade if STEM ready and Register in Univ.

81.5

80.8

0.7

e. Physics

Percent of Cohort Taking Course

81.9

81.4

0.5

Mean Grade

9.1

16.6

$-7.5$

Mean Grade if STEM ready

81.1

80.6

0.5

Mean Grade if STEM ready and Register in Univ.

81.5

81.2

0.3

81.7

81.8

$-0.1$

STEM-readiness and University Registration

Percent of Cohort STEM ready

17.9

18.8

$-0.9$

Percent Register in University

43.5

32.2

11.3

Percent Register and STEM ready

14.5

15.3

$-0.8$

Percent STEM ready if Register in University

33.3

47.4

$-14.1$

Notes: based on cohort of students entering Grade 9 in 2005 at Ontario public schools and observed taking Level 4 (Grade 12) classes within next 5 years. STEM readiness defined as having a minimum of 3 STEM-related courses in Level 4 , including functions, at least one of calculus or biology, and at least one of chemistry or physics. Sample contains 67,994 females and 67,267 males. 
Table 7: Gender Differences in University Registration and STEM readiness

\begin{tabular}{lccccc}
\hline & & & & \multicolumn{2}{c}{$\begin{array}{c}\text { Counterfactual: Give Females } \\
\text { Male Pr(Reg|Not STEM Ready) }\end{array}$} \\
\cline { 5 - 6 } & $\begin{array}{c}\text { Females } \\
(1)\end{array}$ & $\begin{array}{c}\text { Males } \\
(2)\end{array}$ & $\begin{array}{c}\text { Gender Gap } \\
(3)\end{array}$ & $\begin{array}{c}\text { Females } \\
(4)\end{array}$ & $\begin{array}{c}\text { Gender Gap } \\
(5)\end{array}$ \\
\hline Percent STEM-ready & 17.9 & 18.8 & -0.9 & 17.9 & -0.9 \\
Percent Register if STEM ready & 80.9 & 81.2 & -0.3 & 80.9 & -0.3 \\
Percent Register and STEM ready & 14.5 & 15.3 & -0.8 & 14.5 & -0.8 \\
Percent Register if Not STEM ready & 35.3 & 20.9 & 14.5 & 20.9 & 0.0 \\
Percent Register and Not STEM ready & 29.0 & 19.9 & 9.1 & 17.2 & -2.8 \\
Percent Register in University & 43.5 & 32.2 & 11.3 & 31.6 & -0.6 \\
Percent STEM ready if Register & 33.3 & 47.4 & -14.1 & 45.8 & -1.6 \\
\hline Note: Entries derived from samp & & & & & \\
\hline
\end{tabular}

Note: Entries derived from sample described in Table 6. See notes to Table 6 for definition of STEM ready.

${ }^{a}$ Counterfactual under assumption that STEM-ready share of female students and probability of registration conditional on STEM-readiness do not change, but probability of registatation for non-STEM ready females is set to male rate. Under this assumption, female registration rate falls to $31.6 \%$ and percent STEM ready if registered rises to $45.8 \%$ 


\begin{tabular}{|c|c|c|c|c|}
\hline \multirow[b]{2}{*}{$\begin{array}{c}\text { Females } \\
(1)\end{array}$} & \multirow[b]{2}{*}{$\begin{array}{c}\text { Males } \\
(2)\end{array}$} & \multirow{2}{*}{$\begin{array}{c}\text { Gender } \\
\text { Gap } \\
\text { (3) }\end{array}$} & \multicolumn{2}{|c|}{$\begin{array}{c}\text { Counterfactual: Give Females } \\
\text { P(STEM Ready|Track) for Males }\end{array}$} \\
\hline & & & $\begin{array}{c}\text { Females } \\
\text { (4) }\end{array}$ & $\begin{array}{c}\text { Gender Gap } \\
\text { (5) }\end{array}$ \\
\hline
\end{tabular}

\section{A. For Students "On Track" For Level 4 Stem Courses}

1. Prob On Track at End of Level 3

2. Prob. STEM-ready if On Track

54.8

22.4

3.7

26.1

3.7

3. Prob. Register if STEM ready and On-Track

4. Contribution of On Track Students = Row $1 \times$ Row $2 \times$ Row 3

B. For Students "Off Track" For Level 4 Stem Courses

5. Prob. Off Track at End of Level 3

73.9

77.6

$-3.7$

73.9

$-3.7$

6. Prob. STEM ready if Off Track

4.8

5.9

$-1.1$

5.9

0.0

7. Prob. Register if STEM ready and Off-Track

8. Contribution of Off Track Students

= Row $5 \times$ Row $6 \times$ Row 7

C. All Students

9. Percent of Students STEM Ready and

14.5

15.2

$-0.8$

16.9

1.7 Registered in Univ. ( Row $4+$ Row 8)

10. Prob. STEM-ready if Register 33.2

47.4

$-14.1$

37.3

$-10.1$

a/Probabilities of STEM readiness at end of high school for females are recalculated assuming females have same probabilities as males of achieving STEM readiness given either "on track" or "off track" at end of Level 3. Probabilities of being on/off track and probabilities of registration, conditional on STEM readiness and on/off track status are held constant, as are probabilities of registration for students who are not STEM ready. 
Table 9: Gender Gaps in University Readiness and University Registration

\begin{tabular}{|c|c|c|c|c|}
\hline & $\begin{array}{l}\text { All } \\
(1)\end{array}$ & $\begin{array}{c}\text { Female } \\
(2)\end{array}$ & $\begin{array}{c}\text { Male } \\
(3)\end{array}$ & $\begin{array}{c}\text { Gender Gap } \\
\text { (4) }\end{array}$ \\
\hline \multicolumn{5}{|l|}{ A. University Readiness: } \\
\hline Percent University-Ready & 48.0 & 56.1 & 39.9 & 16.2 \\
\hline Uni Ready and STEM ready & 17.3 & 17.2 & 17.4 & -0.2 \\
\hline Uni Ready and not STEM ready & 30.8 & 38.9 & 22.6 & 16.3 \\
\hline Percent not University-Ready & 52.0 & 43.9 & 60.1 & -16.2 \\
\hline \multicolumn{5}{|l|}{ B. University Registration: } \\
\hline Percent Register in University & 37.9 & 43.5 & 32.2 & 11.3 \\
\hline Percent Register If Uni Ready & 75.8 & 75.3 & 76.5 & -1.2 \\
\hline $\begin{array}{l}\text { Pct. Register if Uni Ready and } \\
\text { STEM-ready }\end{array}$ & 84.1 & 83.1 & 85.1 & -2.0 \\
\hline $\begin{array}{l}\text { Pct. Register if Uni Ready and } \\
\text { not STEM ready }\end{array}$ & 71.1 & 71.8 & 69.8 & 2.0 \\
\hline Percent Register If Not Uni Ready & 1.5 & 1.3 & 1.6 & -0.3 \\
\hline \multicolumn{5}{|l|}{ Decomposition: } \\
\hline \multicolumn{5}{|c|}{ Part of University Registration Gap attributable to Gap in University Ready and Not STEM ready } \\
\hline \multicolumn{4}{|c|}{ a. Using Male Rate of Registration if Uni Ready and Not STEM ready } & 11.4 \\
\hline \multicolumn{4}{|c|}{ b. Using Female Rate of Registration if Uni Ready and Not STEM ready } & .7 \\
\hline
\end{tabular}

Notes: See notes to Table 6. University-readiness is defined as having completed at least 5 University Preparation or Mixed Track Level 4 courses. STEM readiness is defined as having a minimum of 3 STEM related level 4 courses. 
Table 10: Components of the Gender Gap in STEM Registration at Entry to University

\begin{tabular}{|c|c|c|}
\hline & $\begin{array}{l}\text { Eemale-Male } \\
\text { Gap }\end{array}$ & $\begin{array}{c}\text { Share of } \\
\text { Overall Gap } \\
(\%)\end{array}$ \\
\hline 1. Gap in Probability of Registering in STEM (conditional on registering) & -13.2 & 100 \\
\hline a. Component due to gap in choice of STEM major if STEM ready & -2.1 & 16 \\
\hline b. Component due to gap in STEM readiness rate & -11.1 & 84 \\
\hline \multicolumn{3}{|l|}{ 2. Of $\mathbf{- 1 1 . 1}$ point gap due to STEM readiness of registrants: } \\
\hline $\begin{array}{l}\text { a. Component due to gap in choice of STEM ready students } \\
\text { to register (numerator effect of equation } 2 \text { ) }\end{array}$ & -1.7 & 13 \\
\hline $\begin{array}{l}\text { b. Component due to gap in registration choices of non STEM-ready } \\
\text { students to register (denominator effect of equation } 2 \text { ) }\end{array}$ & -9.4 & 71 \\
\hline \multicolumn{3}{|l|}{ 3. Of $\mathbf{- 9 . 4}$ point gap due to registration choices of non-STEM ready students: } \\
\hline a. Component due to gap in registration conditional on university readiness & ss 0.0 & 0 \\
\hline b. Component due to gap in university readiness & -9.4 & 71 \\
\hline
\end{tabular}

Notes: see notes to previous tables. Decompositions are formed using average of alterative counterfactuals. 
Appendix Table 1: Effect of Field of Study on Gender Wage Gap for University Educated Workers Age 25-34

\begin{tabular}{|c|c|}
\hline Bachelor Degree & Bachelor Degree or Higher \\
\hline (3) & (4) \\
\hline
\end{tabular}

\section{A. Canada -- 2006 Census}

Female

$-0.103$

$-0.076$

$-0.075$

$-0.107$

$-0.087$

$-0.073$

$$
\text { (0.011) (0.011) }
$$

(0.011)

(0.010) (0.010)

(0.014)

STEM Major
$--\quad 0.188$
(0.012)

$--$

0.154

(0.011)

Field of Study

no

no

yes

no

no

yes

\section{B. United States -- 2009 American Community Survey}

\begin{tabular}{lcccccc} 
Female & -0.160 & -0.142 & -0.118 & -0.158 & -0.139 & -0.117 \\
& $(0.006)$ & $(0.006)$ & $(0.007)$ & $(0.005)$ & $(0.005)$ & $(0.006)$ \\
STEM Major & -- & 0.188 & -- & -- & 0.187 & - \\
$\begin{array}{l}\text { (based on first major) } \\
\text { Field of Study }\end{array}$ & & $(0.007)$ & & & $(0.006)$ & \\
$\begin{array}{l}\text { Controls (10 fields) } \\
\text { no }\end{array}$ & & no & yes & no & no & yes \\
\hline
\end{tabular}

Note: Standard errors in parentheses. Samples includes employed people age 25-34 in 2006 Census or 2009 ACS who were native born or immigrated before age 15 and were not attending school the survey date. Sample in columns 1-3 includes people whose highest degree is a bachelor's degree. Sample in columns 4-6 includes people with a bachelor degree or more. Dependent variable in all models is log of average weekly wage, excluding observations with weekly wage less than $\$ 15$ or over $\$ 4,000$. Canadian sample size in columns $1-3$ is 12,237 ; US sample size is 534,419 . Canadian sample size in columns $4-6$ is 15,772 ; US sample size is 750,035 . All models control for age (grouped variable in Canadian data), part-time status, highest degree, and province/state. 
Appendix Table 2: Field Distribution and Mean Wages by Field for Workers Age 25-34 in 2006 Census

\begin{tabular}{|c|c|c|c|c|c|}
\hline & \multicolumn{2}{|c|}{ Females } & \multicolumn{2}{|c|}{ Males } & \multirow{2}{*}{$\begin{array}{c}\text { Full-Time } \\
\text { Gender Wage } \\
\text { Gap (\%) } \\
\text { (5) }\end{array}$} \\
\hline & $\begin{array}{l}\text { Percent in } \\
\text { Field } \\
(1) \\
\end{array}$ & $\begin{array}{c}\text { Mean Weekly } \\
\text { Wage }^{\mathrm{a}} \\
(2) \\
\end{array}$ & $\begin{array}{l}\text { Percent in } \\
\text { Field } \\
(3)\end{array}$ & $\begin{array}{c}\text { Mean Weekly } \\
\text { Wage }^{\mathrm{a}} \\
(4) \\
\end{array}$ & \\
\hline All Full Time Workers & 100.0 & 1,030 & 100.0 & 1,217 & -16.6 \\
\hline \multicolumn{6}{|l|}{ A. Non-STEM Fields } \\
\hline All Non-STEM Fields & 75.0 & 996 & 62.7 & 1,161 & -15.3 \\
\hline Education, recreation and councelling & 23.0 & 956 & 10.1 & 1,009 & -5.4 \\
\hline Fine and Applied Arts & 3.2 & 817 & 2.6 & 933 & -13.3 \\
\hline Humanities & 12.1 & 892 & 10.2 & 1,032 & -14.6 \\
\hline Social Sciences & 21.4 & 1,000 & 17.3 & 1,176 & -16.2 \\
\hline Commerce and Business & 15.0 & 1,158 & 22.1 & 1,318 & -12.9 \\
\hline \multicolumn{6}{|l|}{ B. STEM Fields } \\
\hline All STEM Fields & 25.0 & 1,157 & 37.3 & 1,315 & -12.8 \\
\hline Biological Sciences and Related & 5.2 & 966 & 3.9 & 1,128 & -15.5 \\
\hline Engineering and Applied Science & 3.7 & 1,357 & 16.9 & 1,369 & -0.9 \\
\hline Health Professions & 11.9 & 1,206 & 4.1 & 1,341 & -10.6 \\
\hline Math, Computer Science, Phy. Sciences & 4.1 & 1,079 & 12.1 & 1,292 & -18.0 \\
\hline
\end{tabular}

Note: Sample includes employed individuals (fulll or part time) in 2006 Census age 25-34 with BA or higher education, not enrolled in school, Canadian-born or immigrated before age 16 .

${ }^{a}$ Mean weekly wage calculated for BA graduates, age 30-34, working full time. 
Appendix Table 3: Characteristics of New University Entrants ("Registrants")

\begin{tabular}{|c|c|c|c|c|}
\hline & \multicolumn{2}{|c|}{ All Students } & \multicolumn{2}{|c|}{ STEM Registrants } \\
\hline & Female & Male & Female & Male \\
\hline Number of students & 237,719 & 175,894 & 72,124 & 76,489 \\
\hline Canadian Born & $94.1 \%$ & $92.7 \%$ & $91.7 \%$ & $90.2 \%$ \\
\hline Permanent Resident & $5.2 \%$ & $6.4 \%$ & $7.6 \%$ & $8.9 \%$ \\
\hline Study Visa or Other & $0.7 \%$ & $0.9 \%$ & $0.8 \%$ & $0.9 \%$ \\
\hline Home Language $=$ English & $79.5 \%$ & $77.3 \%$ & $73.6 \%$ & $72.1 \%$ \\
\hline Home Language $=$ French & $3.0 \%$ & $2.3 \%$ & $3.4 \%$ & $2.5 \%$ \\
\hline Home Language $=$ Other & $17.5 \%$ & $20.4 \%$ & $23.1 \%$ & $25.4 \%$ \\
\hline Age $=17$ & $1.2 \%$ & $1.1 \%$ & $1.8 \%$ & $1.6 \%$ \\
\hline Age $=18$ & $82.0 \%$ & $71.6 \%$ & $83.7 \%$ & $76.1 \%$ \\
\hline Age $=19$ & $15.6 \%$ & $25.1 \%$ & $13.2 \%$ & $20.3 \%$ \\
\hline Age $=20$ & $1.3 \%$ & $2.2 \%$ & $1.3 \%$ & $2.1 \%$ \\
\hline $\begin{array}{l}\text { Mean Grade - Top } 6 \text { Courses } \\
\text { (standard deviation) }\end{array}$ & $\begin{array}{l}83.27 \\
(6.35)\end{array}$ & $\begin{array}{l}82.24 \\
(6.65)\end{array}$ & $\begin{array}{l}85.14 \\
(6.33)\end{array}$ & $\begin{array}{l}84.05 \\
(6.63)\end{array}$ \\
\hline
\end{tabular}

Note: Sample includes OUAC applicants from Ontario public high schools in years 2005-2017 who were between the ages of 17 and 20 and were recorded as registering in an Ontario university in the fall after the year of their application. A small number of applicants $(n=1,038)$ with missing high school course information are excluded. 
Appendix Table 4: Characterstics of Students in High School Cohort

\begin{tabular}{lccc}
\hline & All Students & Females & Males \\
\hline Number of Students & 135,261 & 67,994 & 67,267 \\
Special Needs & $7.9 \%$ & $5.3 \%$ & $10.5 \%$ \\
Gifted & $2.1 \%$ & $1.7 \%$ & $2.5 \%$ \\
Born Outside Canada & $11.2 \%$ & $11.1 \%$ & $11.3 \%$ \\
Attended Catholic High School in Level 1 (Grade 9) & $34.1 \%$ & $34.6 \%$ & $33.7 \%$ \\
Participation in Academic Track Math Courses: & & & \\
Took Academic Math in Level 3 (Grade 11) & $40.9 \%$ & $41.9 \%$ & $39.9 \%$ \\
Took Academic Math in Level 1 (Grade 9) & $30.0 \%$ & $31.3 \%$ & $28.6 \%$ \\
$\quad$ but not Level 3 (Grade 11) & & & \\
All other permutations & $29.1 \%$ & $26.8 \%$ & $31.5 \%$ \\
Post Secondary Schooling Participation & & & \\
Applied to Ontario University & $48.0 \%$ & $54.6 \%$ & $41.3 \%$ \\
Applied to Ontario 2-3 Year College & $35.3 \%$ & $35.1 \%$ & $35.5 \%$ \\
Entered Ontario University & $37.8 \%$ & $43.5 \%$ & $32.2 \%$ \\
Entered Ontario College & $26.4 \%$ & $25.9 \%$ & $26.9 \%$ \\
\hline
\end{tabular}

Notes: sample includes students who entered grade 9 in Fall 2005 at age 14 or 15 and took a full course load, have complete information on their Level 1 (Grade 9) math and language course selections and grades, and are observed taking at least one Level 4 course within the next 5 years. Students at small rural schools are also excluded. 